\title{
Prevalence and impact of risk factors for poor asthma outcomes in a large, specialist-managed patient cohort: a real-life study
}

This article was published in the following Dove Press journal: Journal of Asthma and Allergy

\author{
Gábor Tomisa ${ }^{1,2}$ \\ Alpár Horváth ${ }^{1,2}$ \\ Zsuzsanna Szalai ${ }^{3}$ \\ Veronika Müller ${ }^{\prime}$ \\ Lilla Tamási ${ }^{1}$ \\ 'Department of Pulmonology, \\ Semmelweis University, Budapest II 25, \\ Hungary; ${ }^{2}$ Chiesi Hungary Ltd, Budapest \\ 1 138, Hungary; ${ }^{3}$ Petz Aladár County \\ Teaching Hospital, Győr 9023, Hungary
}

Correspondence: Gábor Tomisa

Department of Pulmonology, Semmelweis

University, Diós árok I/C, Budapest II25,

Hungary

Tel +36209786986

Email g.tomisa@chiesi.com
Background: Risk factors for poor asthma outcomes may have considerable influence on the control level and medical care of asthmatic patients. Our objective was to conduct a study that provides data on the level of symptom control and the frequency of specific risk factors for poor asthma outcomes on a large patient cohort.

Methods: A cross-sectional, non-interventional real-life study was conducted among asthmatic patients treated by respiratory specialists in Hungary. Asthma control and risk factor assessment were done according to Global Initiative for Asthma guideline (Box 2-2). In the data analysis, phase descriptive statistics, graphical outputs, and Fisher's exact tests were used.

Results: Of 12743 patients enrolled by 187 specialists, asthma was well controlled in $36.0 \%$, partially controlled in $29.29 \%$, and uncontrolled in $34.71 \%$ of the cases. The most common comorbidities were rhinitis/sinusitis (66.84\%), cardiovascular diseases (43.81\%), and gastroesophageal reflux disease $(20.11 \%)$. The following risk factors had the strongest relationship with uncontrolled disease: incorrect inhaler technique causing side effects (odds ratio, OR 4.86, 3.51-6.8), previous severe exacerbation (OR 4.79, 4.02-5.72), high short-acting beta agonist (SABA) use (OR 4.46, 4.03-4.93), incorrect inhaler technique associated with an exacerbation

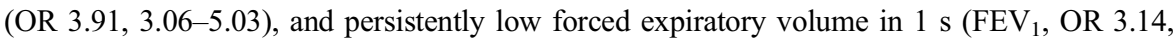
2.8-3.52). The most frequent risk factors were smoking (OR 1.47, 1.36-1.59) and obesity (OR $1.34,1.24-1.45)$. Furthermore, high loss of control was associated with an initial low FEV (OR 2.21, 2.01-2.44), frequent oral corticosteroid (OCS) use (OR 1.83, 1.64-2.05), poor adherence to treatment (OR 2.51, 2.21-2.86), and allergen exposure (OR 1.63, 1.47-1.81).

Conclusions: This study indicated that the presence of risk factors for poor asthma outcomes listed by the Global Initiative for Asthma document significantly influenced actual control level in a real-world large patient cohort, with high SABA use, previous severe exacerbation, incorrect inhaler technique, persistently low $\mathrm{FEV}_{1}$, and poor adherence to treatment having the highest impact.

Keywords: asthma, risk factors, poor outcomes, exacerbation, reliever use, comorbidity

\section{Background}

Asthma is a chronic pulmonary disease with considerable economic burden. ${ }^{1}$ In 2015, asthma was the most prevalent chronic respiratory disease, affecting 358 million people, meaning twice the number of cases compared to chronic obstructive pulmonary disease (COPD). ${ }^{2}$

The prevalence of asthma in Hungary was found to be $7.6 \%$, which corresponds to the European average. ${ }^{3}$ International strategies set forth by the Global Initiative for 
Asthma (GINA) document, as well as the local national asthma guideline, help in effective clinical management and propose therapeutic decisions to be made based on the level of asthma control. The aim of asthma treatment is to achieve a controlled condition and to maintain it on the long term. ${ }^{4}$ Despite the presence of established treatment guidelines and high accessibility to inhaled therapies, asthma morbidity is significant, and many asthma patients still experience persistent symptoms, poor disease control, and exacerbations. ${ }^{5,6} \mathrm{~A}$ recent European study of 8000 asthmatic patients treated in general practice showed that $45 \%$ of them were uncontrolled and $44 \%$ required at least 1 course of oral corticosteroids in the last year. ${ }^{7}$ Poor asthma control is associated with negative outcomes, including impaired health-related quality of life (HR-QoL), great use of health care resources, work, and activity impairment, resulting in substantial direct and indirect costs. ${ }^{4,8}$ At the same time, negative outcomes of asthma are associated with risk factors some of which are modifiable. $^{6}$

The GINA 2014 document was the first to formally describe asthma evaluation beyond control assessment. ${ }^{4}$ Achieving and maintaining a controlled condition is still an important aim of asthma treatment; however, decreasing the risks of negative outcomes caused by asthma is also a top priority. Minimizing the risk of poor asthma outcomes, namely future exacerbations, development of fixed airflow limitation, and side effects, are also aims of asthma management. Consequently, the therapeutic strategy is not merely determined by symptom control, but also identifying the specific risk factors of poor asthma outcomes. Poor asthma symptom control itself increases the risk of exacerbations. ${ }^{9}$ However, up till now, the frequency of specific risk factors for poor asthma outcomes determined by the GINA document, together with their relationship to disease control have not yet been evaluated. There is no full-scale GINA determined risk factor assessment in a large asthmatic population, either in a national or international cohort, and consequently, no reliable data are available in respect to how much the presence of a specific risk factor influences current control.

Our study was designed to examine not only the current asthma control but also the importance and impact of certain risk factors determined by the GINA document and their relationship to uncontrolled status. Our objective was to conduct a wide-ranging, representative real-life study in asthma, which would provide data both on symptomatic control level and the frequency of risk factors associated with poor asthma outcomes in a specialist treated patient population.

\section{Methods}

\section{Selection of the patients}

This was a non-interventional cross-sectional study under real-life circumstances. Inclusion of the patients and data recording was performed on a single occasion. For detailed data collection purposes, a doctor and a patient questionnaire were developed. In order to eliminate seasonal effects, patient recruitment was carried out throughout an entire year (from 11-05-2015 to 19-05-2016). To obtain a non-biased patient enrolment, every health institution could include a maximum of 15 patients on 5 predetermined consecutive workdays per month. Enrolment was conducted randomly with the inclusion of consecutive asthma patients who wished to participate. Given that in Hungary, pulmonologist specialists have the exclusive responsibility to diagnose and treat asthma patients, the examinations and data collection were done solely by respiratory specialists. The enrolment of patients took place in dispensaries, outpatient clinics specializing in pulmonology, and in outpatient departments of hospitals in all regions of Hungary. Table 1 contains the inclusion and exclusion criteria of the study.

The designing and the implementation of the study were carried out observing good clinical practice (GCP guidelines) and the Declaration of Helsinki. Patients were included in the study on a voluntary basis after providing them with information and after signing a written contract, without any remuneration.

\section{Recorded data}

A comprehensive data collection form was used to record patient demographic characteristics, major medical history, smoking habits, comorbidities, risk factors, current control

Table I Inclusion and exclusion criteria

\begin{tabular}{|l|l|}
\hline Inclusion criteria & Exclusion criteria \\
\hline - Adult asthmatic patients & - Lack of consent by patient \\
- Asthma diagnosis for & - Inability to complete patient related \\
$>6$ months & questionnaires \\
- Maintenance therapy & - Permanent need for maintenance \\
unchanged in the last & systemic corticosteroid treatment \\
month & - Acute exacerbations at time of \\
- Out-patient & inclusion in study \\
- No hospitalisation in the & - Active tuberculosis \\
last month & - Malignant disease in a palliative \\
- No significant, untreated & treatment phase \\
chronic disease & \\
\hline
\end{tabular}


state, medications, and all relevant physical assessments. Laboratory tests were not performed. Asthma control, treatment steps, and risk factor assessment were done according to GINA 2014 (Box 2-2 and Box 3-5.). The treatment steps were derived from actual prescribed maintenance therapy. Comorbidities, allergen history, hospitalization, previous intubation, low initial forced expiratory volume in $1 \mathrm{~s}\left(\mathrm{FEV}_{1}\right)$ at the time of diagnosis, and the time of asthma diagnosis were collected by reviewing clinical records of enrolled patients. BMI was calculated based on the patient's measured height and weight at the time of examination. Poor adherence was defined by the physician based on the patient's data. In addition, data from the patient survey were also documented. If spirometry was performed on the medical visit of the patient, $\mathrm{FEV}_{1}$, forced vital capacity $(\mathrm{FVC})$, and $\mathrm{FEV}_{1} / \mathrm{FVC}$ were recorded.

\section{Statistical analysis}

Data collection and database management were conducted by AdWare Research Ltd. (Balatonfüred, Hungary), and the statistical analysis by Adatrendezö Ltd. (Budapest, Hungary). In the data analysis phase, descriptive statistics, graphical outputs, and Fisher's exact tests were used. Odds ratios were provided with $95 \%$ confidence intervals (CI). For statistical analysis, we used the open source Python 2.7.12 on a MAC operating system (Anaconda Inc., Austin, TX) and R for Windows 3.4.2 (R Core Team 2017., R: A language and environment for statistical computing. R Foundation for Statistical Computing, Vienna, Austria. URL https://www.R-project.org/).

\section{Results}

During the 1-year period of inclusion, an average of 69 patients were included per investigational sites. This involved 187 centers, representing $35 \%$ of the pulmonologists currently working in outpatient medical clinics in Hungary. Table 2 contains the demographic data and main clinical characteristics of the included 12743 patients.

Concerning age distribution, $9.9 \%$ of the patients were 18-30 years, $19.4 \%$ were $31-45$ years, $44.6 \%$ were $46-65$ years old, and $26.1 \%$ were older than 65 years. Patients diagnosed with asthma for more than 1 year represented $97.4 \%$ of the cohort. Men represented 31.9\%. With respect to seasonality, $54.3 \%$ of the patients were examined from April to September, while $45.7 \%$ were examined from October to March. Patient inclusion was also in line with population densities in the geographical regions. The majority of patients received maintenance therapy on GINA step 2, 3, and 4.

Patients who had never smoked represented $66.5 \%$ of the cohort, $20.3 \%$ had smoked previously, yet quit, and $13.1 \%$ were smokers at the time of the examination. The average body mass index (BMI) was $28.46 \pm 5.7 \mathrm{~kg} / \mathrm{m}^{2}$. Mean forced expiratory flow in $1 \mathrm{~s}\left(\mathrm{FEV}_{1}\right)$ value was $84.29 \%(2.34 \mathrm{~L})$, mean forced vital capacity (FVC) 94.18\% (3.13 L), and mean $\mathrm{FEV}_{1} / \mathrm{FVC} 83.74 \%$. Regarding the $\mathrm{FEV}_{1}, 38.2 \%$ of the patients had values lower than $80 \%$ predicted, and $11.5 \%$ of the patients had values lower than $60 \%$.

Table 3 summarizes the medically diagnosed comorbidities of the whole patient population.

The most commonly recorded comorbidities $(66.84 \%$ of all patients) were rhinitis and/or sinusitis. Cardiovascular disease was the second, affecting $43.81 \%$ of all patients. Gastroesophageal reflux disease (GERD) was diagnosed in $20.11 \%$ and COPD in $7.86 \%$ of the patients.

Measuring asthma control was mandatory in all cases, and the results are summarized in Figure 1. Well-controlled asthma was found in $36.0 \%$ of the patients; however, in $29.29 \%$ of the patients, it was partially controlled, and in $34.71 \%$ of the cases, asthma was uncontrolled.

The risk factors of poor asthma outcomes determined by the GINA document (exacerbation, fixed airway obstruction, and side effects of medications) were also recorded. Table 4 and Figures S1-S3 contain control level of patients together with the specific risk factors.

Among the risk factors named by the GINA and detected in our study, improper inhaler technique which caused side effects showed the strongest relation to an uncontrolled state (OR 4.86, CI 3.51-6.8). As high as $71.58 \%$ of the affected patients were uncontrolled. The second highest OR of 4.79 was observed for patients who had at least 1 severe exacerbation in the last 12 months; 70.05\% were uncontrolled. Patients with high short-acting beta agonist (SABA) use were also predisposed to loss of asthma control, with $64.55 \%$ were uncontrolled (OR 4.46, CI 4.03-4.93). The fourth highest OR (3.91, CI 3.06-5.03) was found in those with incorrect inhaler technique associated with an exacerbation.

Poor adherence to ICS showed a strong relation to uncontrolled disease in our study as $55.11 \%$ were uncontrolled, resulting in an OR of 2.51 (CI 2.21-2.86). Low $\mathrm{FEV}_{1}$ at diagnosis had an OR of 2.21 (CI 2.01-2.44) for loss of asthma control. As an initially low $\mathrm{FEV}_{1}$ value predisposed an uncontrolled state, an actual low $\mathrm{FEV}_{1}$ was 
Table 2 Main demographic data, clinical characteristics and lung function parameters of patients

\begin{tabular}{|c|c|c|c|}
\hline & & \multicolumn{2}{|c|}{ Study population } \\
\hline & & $\mathbf{N}$ & $\%$ \\
\hline \multicolumn{2}{|l|}{ Number of patients } & 12743 & 100 \\
\hline \multirow[t]{3}{*}{ Number of cases in regions of Hungary } & East & 5149 & 40.4 \\
\hline & West & 3984 & 31.3 \\
\hline & Central & 3610 & 28.3 \\
\hline \multirow[t]{2}{*}{ Examined patients according to seasonality } & April-September & 6923 & 54.3 \\
\hline & October-March & 5820 & 45.7 \\
\hline \multirow[t]{6}{*}{ Years since the diagnosis of asthma } & $0-1$ years & 310 & 2.4 \\
\hline & $2-5$ years & 3280 & 25.7 \\
\hline & $6-10$ years & 3295 & 25.9 \\
\hline & $\mathrm{II}-20$ years & 3930 & 30.8 \\
\hline & $>20$ years & 1913 & 15.0 \\
\hline & No data & 15 & 0.1 \\
\hline \multirow[t]{5}{*}{ GINA based treatment categories } & STEP I & 274 & 2.15 \\
\hline & STEP 2 & 990 & 7.77 \\
\hline & STEP 3 & 4759 & 37.35 \\
\hline & STEP 4 & 6390 & 50.14 \\
\hline & STEP 5 & 330 & 2.59 \\
\hline \multirow[t]{2}{*}{ Gender } & Male & 4059 & 31.9 \\
\hline & Female & 8684 & 68.1 \\
\hline \multirow[t]{4}{*}{ Smoking habit } & Smoker & 1669 & 13.1 \\
\hline & Former smoker & 2584 & 20.3 \\
\hline & Never smoked & 8476 & 66.5 \\
\hline & No data & 14 & 0.1 \\
\hline \multirow[t]{4}{*}{ Age distribution } & $18-30$ & $|26|$ & 9.9 \\
\hline & $31-45$ & 2466 & 19.4 \\
\hline & $46-65$ & 5687 & 44.6 \\
\hline & $>65$ & 3329 & 26.1 \\
\hline \multirow[t]{5}{*}{ Body mass index distribution } & $<18.5$ & 228 & 1.8 \\
\hline & $18.5-24.9$ & 3453 & 27.1 \\
\hline & $25-29.9$ & 4487 & 35.2 \\
\hline & $30-34.9$ & 3009 & 23.6 \\
\hline & $\geq 35$ & 1566 & 12.3 \\
\hline \multirow[t]{4}{*}{ 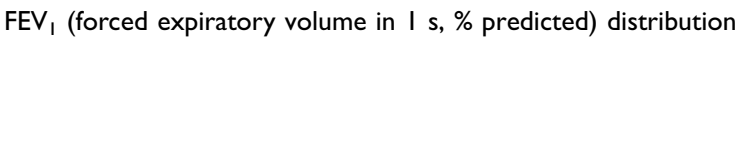 } & $>80 \%$ & 7527 & 59.1 \\
\hline & $60-80 \%$ & 3399 & 26.7 \\
\hline & $<60 \%$ & $|46|$ & 11.5 \\
\hline & No data & 356 & 2.8 \\
\hline
\end{tabular}

Abbreviation: GINA, global initiative for asthma.

a stronger risk factor for uncontrolled disease (OR 3.14, CI 2.8-3.52).

Inhaled noxious chemicals or occupational exposures excluding smoking affected $48.68 \%$, who were poorly controlled (OR 1.86, 1.6-2.15). Smoking affected 4253 patients, and poor control was present in $40.58 \%$ of them
(OR 1.47, 1.36-1.59). The most common risk factor was the presence of chronic rhinosinusitis. A history of allergies was found in 8517 patients, with similar disease control as the whole cohort; however, out of 1786 patients who had an allergic condition at the time of examination, $44.62 \%$ were uncontrolled and demonstrated an OR of 
Table 3 Comorbidities of study participants (data are presented as numbers and percentages)

\begin{tabular}{|l|l|l|}
\hline Comorbidities & N & $\%$ \\
\hline Cardiovascular disease & 5583 & 43.81 \\
Hypertension & 5226 & 41.01 \\
Cardiac insufficiency & 1250 & 9.81 \\
Acute myocardial infarction & 210 & 1.65 \\
Atrial fibrillation (chronic) & 160 & 1.26 \\
Other cardiac arrhythmia & 731 & 5.70 \\
Other cardiac history & 215 & 1.69 \\
Rhinitis and/or Sinusitis & 8517 & 66.84 \\
Gastroesophageal reflux disease (GERD) & 2563 & 20.11 \\
Diabetes & 1129 & 8.86 \\
Impaired glucose tolerance (IGT) & 1058 & 8.30 \\
Concomitant COPD & 1002 & 7.86 \\
Osteoporosis & 1081 & 8.48 \\
Prostate hyperplasia & 317 & 2.49 \\
Glaucoma & 227 & 1.78 \\
Cerebrovascular events & 311 & 2.44 \\
Other comorbidities & 1320 & 10.36 \\
\hline
\end{tabular}

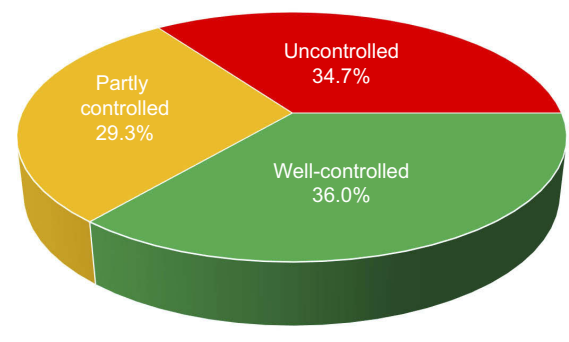

-Well-controlled = Partly controlled - Uncontrolled

Figure I Proportion of patients with different levels of asthma control according to GINA guideline.

1.63 (1.47-1.81) for loss of asthma control. In 1513 patients, systemic corticosteroid treatment was necessary, and poor asthma control was observed in $47.46 \%$ of them. Frequent OCS related to systemic side effects resulted in a high uncontrolled level (OR 1.83, 1.64-2.05). In 4575 cases, the BMI was $>30 \mathrm{~kg} / \mathrm{m}^{2}$, and $39.04 \%$ of these patients were poorly controlled (OR 1.34, CI 1.24-1.45).

\section{Discussion}

In Hungary, similarly to many countries of Eastern Europe, the diagnosis and treatment of asthmatic patients is the responsibility of the pulmonologists. A whole range of therapeutic options suggested by the GINA guidelines is available. Nonetheless, based on the current study, which was the largest study examining asthma control in Eastern Europe, 36\% of the patients were well controlled, $29.29 \%$ were partially controlled, and $34.71 \%$ were uncontrolled.

Regarding the rate of controlled asthma, our investigation demonstrated nearly equivalent result to a recent specialist-based cross-sectional study of adult asthma in Japan. Adachi et al found, despite receiving treatment from an allergy and/or respiratory specialist, only $35.1 \%$ of the patients had controlled asthma. ${ }^{10}$ In Turkey, Gemicioglu et al observed the same rate of controlled patients. The percentage of patients with total control in the elderly and young groups were $33.9 \%$ and $37.1 \%$ at first visit. ${ }^{11}$ These results draw attention to the need for improving asthma management. There is growing evidence that environmental pollution aggravates asthma. One limitation is that this factor has not been studied. ${ }^{12}$

Uncontrolled disease may be related to the presence of risk factors documented by the GINA guidelines. This current study was the first large-scale, specialist-evaluated cohort which aimed to determine the frequency of specific risk factors identified by the GINA document. Our aim was to validate the known risk factors of non-control in a large asthma cohort in real life. Based on the data collected by pulmonologists during patient visits, GINA defined risk factors for poor asthma outcomes proved to be related to uncontrolled disease; the strength of this relationship varied depending on the risk factor. In everyday clinical practice, it is important to know that the frequencies and the relationships to poor control of listed risk factors vary over a wide range.

The frequency of specific risk factors and the odds ratio of its relationship with control loss are visualized in Figure 2. The risk factors that appear more frequently than average and those which strongly linked to a poor outcome should be prioritized and monitored continuously.

In our study, besides excessive SABA use, yearly exacerbating disease pattern, improper inhaler technique, and low $\mathrm{FEV}_{1}(<60 \%$ predicted) were the most strongly related to suboptimal disease control. It was not surprising that high SABA use had an especially high OR. Of the patients who used more than 1 pack of salbutamol a month, $64.55 \%$ were uncontrolled at the time of the survey, and in total only $13 \%$ of them were well controlled. This result clearly shows that there is an overuse of salbutamol that is related to uncontrolled disease.

Similarly to high SABA use, the chance of an uncontrolled status (eg, exacerbations) amongst patients who had at least 1 severe exacerbation per year was exceedingly high. This confirms the results of the TENOR Study Group 


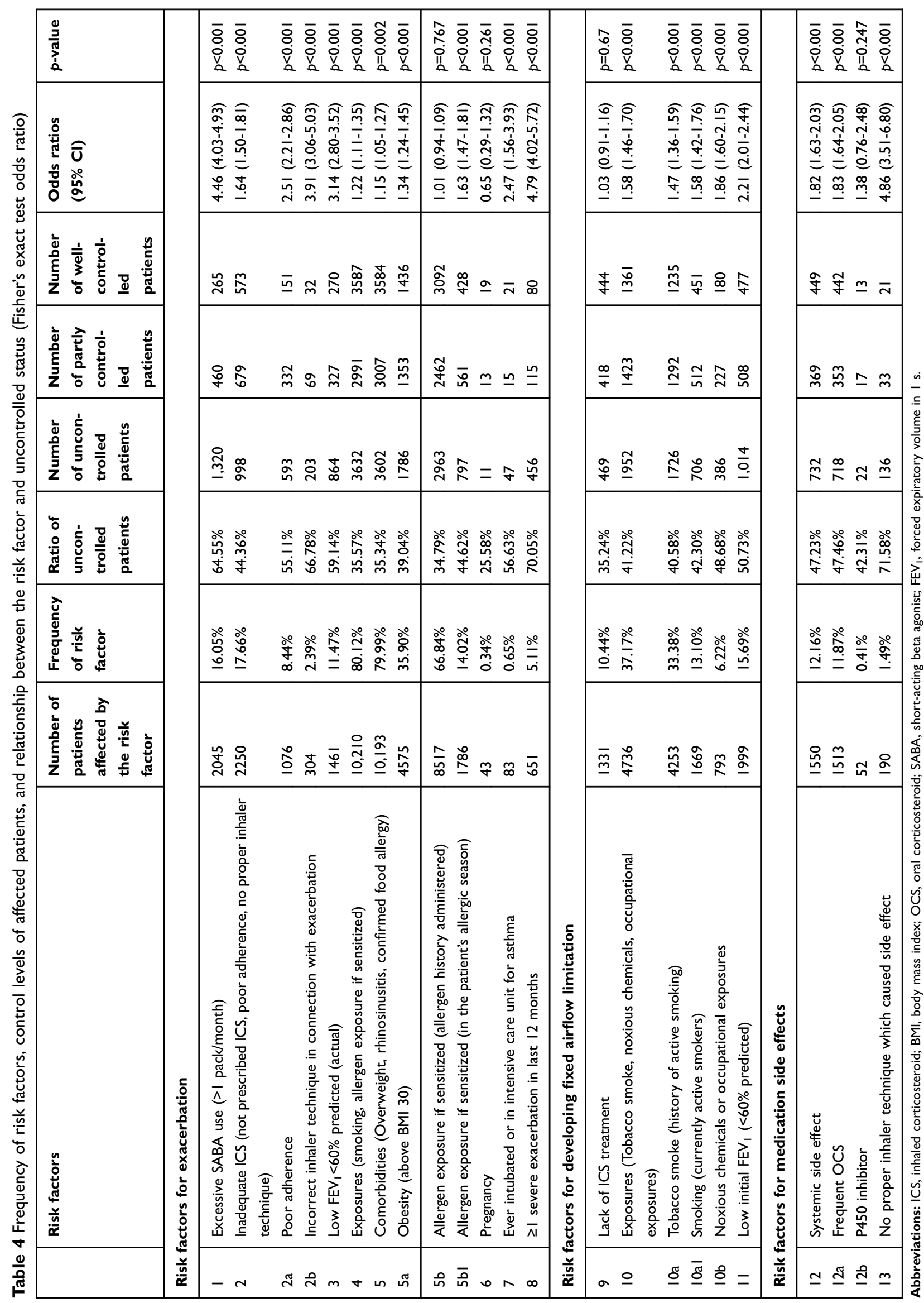




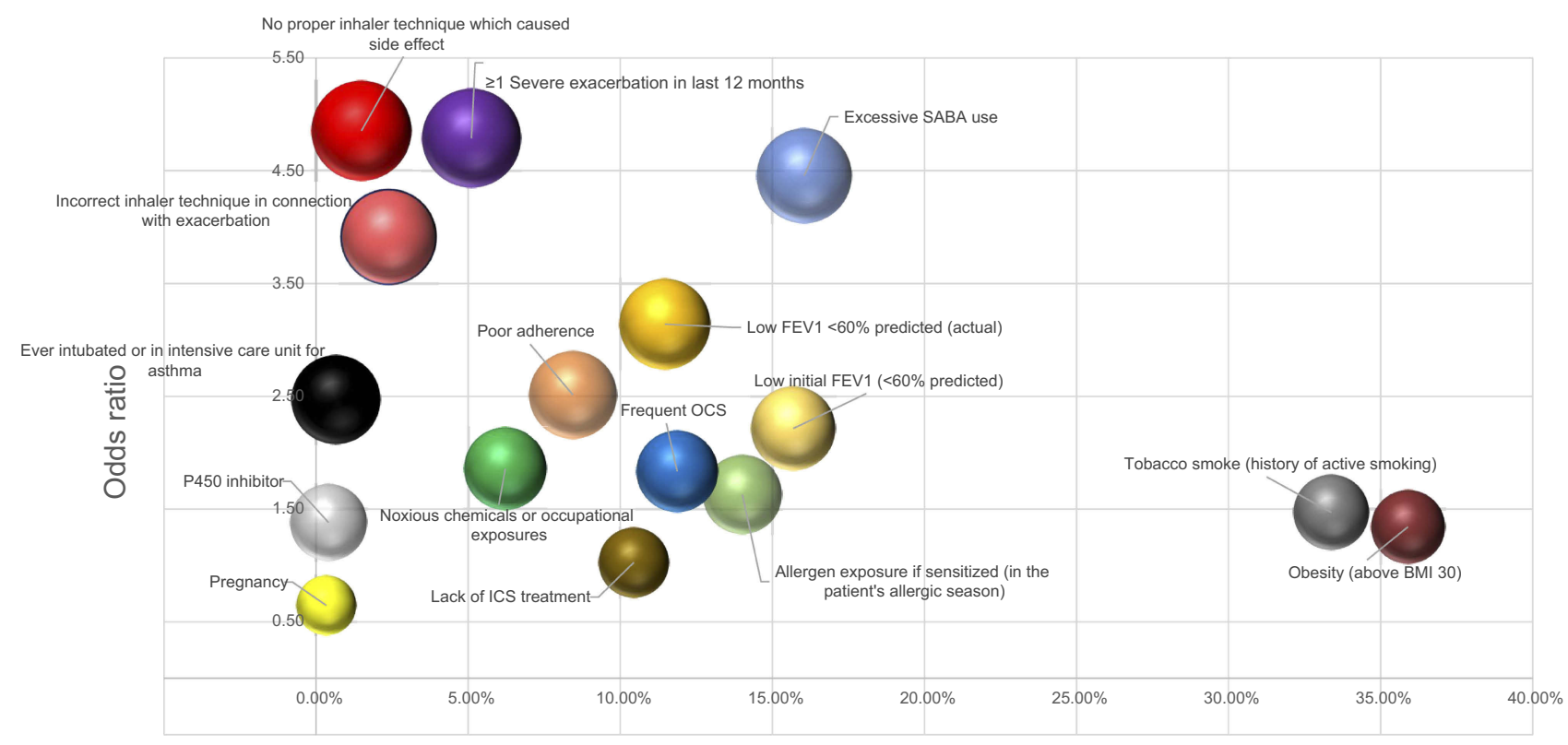

Frequency of risk factor (\%)

Figure 2 The frequency of specific risk factors and the odds ratio of its relationship with uncontrolled status. Note: Size of bubbles represent the ratio of uncontrolled patients.

Abbreviations: BMI, body mass index; ICS, ICS, inhaled corticosteroid; OCS, oral corticosteroid; FEV

that severe asthma exacerbations are a strong independent factor predicting future exacerbations. ${ }^{13}$ Although patients in acute exacerbation were excluded from our study, $5.11 \%$ of the patients had severe exacerbation within the last year, and $70.05 \%$ of them were poorly controlled at the time of the study.

Incorrect inhaler technique was recorded in two aspects listed in the GINA guideline. In the present study, incorrect inhaler technique showed a strong relationship to uncontrolled status. This is in line with a recent study, which showed that incorrect inhaler technique seems to be frequent in real-life settings. Melani et al found that $12-43.5 \%$ of the patients make at least 1 critical error in inhalation technique, and hospitalization or emergency department visit due to these errors occurred in $30 \%$ of the patients. ${ }^{14}$ The study showed that different failures of device use may lead to different levels of impairment to successful therapy. Incorrect inhaler technique in real-life setting may be an important risk factor to loss of control (named as poor asthma outcome in our study) and also exacerbations, because poor inhaler technique may cause low drug deposition resulting in deterioration of the effect of the drug. On the other hand, improper inhaler technique may worsen drug adherence. Thus, educational programs, which are inexpensive and effective, may help in preventing the development of loss of asthma control. ${ }^{15,16}$
Data recording of incorrect inhaler technique on the other hand represents a limitation of our study, as it was the doctors' task to determine inhalation technique, and also whether the patient had an exacerbation or side effect due to incorrect inhaler technique. GINA underlines the fact that low $\mathrm{FEV}_{1}$ is known to be a strong independent predictor of future exacerbations. Our results are in concordance with these findings, both when low $\mathrm{FEV}_{1}$ was measured at the time of diagnosis or with maintenance therapy. However, our results raise a hypothesis that patients are at higher risk of poor outcomes if their low $\mathrm{FEV}_{1}$ exists despite the use of maintenance therapy. Although we experienced low $\mathrm{FEV}_{1}$ in only $11.47 \%$ of our patients, it may be considered as a very strong predictor of uncontrolled status with an OR of 3.14. Interestingly, low initial $\mathrm{FEV}_{1}$ values also showed a significant relationship to loss of asthma control, with an OR of 2.21. Our results were consistent with those of Osborne and co-workers, who found that patients with low $\mathrm{FEV}_{1}$ at any time of their life are at a significantly higher risk of exacerbations, which underscores the importance of spirometry in asthma care. ${ }^{17}$

Notably in our study, the incidence of frequent OCS users was high, and despite the effective systemic effect of this medication, their control was significantly lower than average. In the CHAS study, Gonzalez et al observed a high level of uncontrolled asthma (63.9\%) which was strongly associated with oral corticosteroid treatment $(\mathrm{OR}=6.55) .{ }^{18}$ 
In our investigation, the incidence of poor adherence to treatment was lower than in other specific adherencefocused studies. ${ }^{19,20}$ Our method had limitations in recognizing all non-adherent patients, which may be the consequence of deficiencies in the collection of adherence data by specialists in everyday clinical practice. However, our results still confirmed the well-established evidence of poor adherent patients having a high probability of an uncontrolled status. $^{21}$

Three risk factors were identified in our study affecting a high number of patients but having a weaker relationship with loss of asthma control. The smoker group represented $33.38 \%$ of all the patients and was related to suboptimal control with an OR of 1.47. Smoking is a frequent factor behind suboptimal asthma control, with the risk of evolving COPD. Among smokers, $13.1 \%$ of the patients were currently active smokers and their OR was 1.58 (CI 1.421.76). Consequently, active smoking may be considered as a frequent factor behind suboptimal asthma control. Furthermore, for ex-smokers, the chance of poor outcome remains higher for a long time after quitting.

Many studies support an association between obesity and asthma prevalence. ${ }^{22-28}$ It has also been proved that patients with obesity are more likely to have uncontrolled asthma compared to eutrophic patients. ${ }^{29}$ Additionally, an association between obesity and increased asthma severity in adults has been demonstrated. ${ }^{30}$ The National Asthma Survey, one of the largest asthma surveys in the USA, showed that obesity is associated with several measures of asthma severity and control, including symptoms, missed workdays, medication use, and GINA severity classification. ${ }^{31}$ In our study, the risk of an uncontrolled status was also higher due to obesity.

A history of rhinosinusitis or food allergy was especially prevalent amongst Hungarian asthmatic patients; however, it showed no strong relationship with poor asthma outcomes. Inhaled allergens cause problems and symptoms at a specific time of the year. Therefore, we separately analyzed the patient group who had seasonal allergies at the time of data registration. Out of 1786 patients who were examined in their sensitized allergen period, $44.62 \%$ had bad asthma control, which was higher compared to the rest of the patients and correlated significantly with a higher chance for bad asthma outcomes. A limitation of our study is that bronchiectasis was not actively screened, which could impact on control status of moderate to severe asthma patients. ${ }^{32}$ Finally, we identified infrequent risk factors as well which were less likely to worsen asthma control.
Patients who had been pregnant in the last 12 months represented $0.34 \%$ of the cohort, but this condition had hardly any effect on current asthma control. At the time of enrolment, 43 patients were pregnant; however, due to the smaller number of participants, it was not possible to reliably determine what effect pregnancy had on current asthma state. The rate of the side effects that stem from the co-administration of a P450 inhibitor compared to the examined risk factors is still an important result despite its lower incidence. The risk of uncontrolled asthma was not associated with a lack of ICS. The reason for this may be that pulmonologists underestimate the lack of ICS resulting from non-adherence. On the other hand, there could be a patient population who used maintenance therapy as needed without losing control of their asthma. This hypothesis was supported by Papi et al, who found that patients with mild persistent asthma who have infrequent symptoms may not require regular treatment with inhaled corticosteroids. $^{33}$

\section{Conclusion}

The results of this large real-world study, conducted for the first time in Eastern Europe by respiratory specialists, may contribute to uncovering the most important causes of poor asthma control in everyday clinical practice, together with determining the impact of different risk factors in leading to poor asthma outcomes, thus gaining a better understanding of the disease. We found that the risk factors listed by the GINA document significantly influence the control level of asthmatic patients. High SABA use, exacerbation history, incorrect inhaler technique, persistently low $\mathrm{FEV}_{1}$, and poor adherence to treatment are of outstanding significance in influencing asthma control and leading to poor outcomes. In order to further improve disease control, substantial attention might be paid to recognizing risk factors for poor asthma outcomes.

\section{Abbreviation list}

$\mathrm{OR}$, odds ratio; CI, confidence intervals; COPD, chronic obstructive pulmonary disease; GINA, Global Initiative for Asthma; HR-QoL, health-related quality of life; eCRF, electronic case report form; GCP, good clinical practice; $\mathrm{FEV}_{1}$, forced expiratory volume in $1 \mathrm{~s}$; $\mathrm{FVC}$, forced vital capacity; BMI, body mass index; GERD, gastroesophageal reflux disease; IGT, Impaired glucose tolerance; SABA, short-acting beta agonist; ICS, inhaled corticosteroid, ICU, intensive care unit. 


\section{Ethics approval and consent to participate}

All procedures were performed in accordance with the ethical standards of the National Scientific and Research Ethics Committee of Hungary (ad.7864-2/2015/EKU [ad.48/2015]) and with the 1964 Helsinki Declaration and its later amendments or comparable ethical standards.

\section{Availability of data and materials}

The datasets used and/or analyzed during the current study are available from the corresponding author on reasonable request.

\section{Acknowledgments}

The authors thank to Abonyi-Tóth Zsolt (Data Processor Ltd.) for statistical analysis and to Proof-Reading-Service. com Ltd. for language check. The study was funded by Chiesi Hungary Ltd.

\section{Author contributions}

GT contributed to conception and design of the study, to literature search, and writing the manuscript. AH participated in literature search and made contributions to the acquisition and interpretation of data, and revised the manuscript. VM contributed to the literature search and revised the manuscript. LT and ZS contributed to conception and design of the study, to the acquisition and interpretation of data, and revised the manuscript. All authors contributed to data analysis, drafting and revising the article, gave final approval of the version to be published, and agree to be accountable for all aspects of the work.

\section{Disclosure}

VM, LT, and ZS had consultant arrangements with AstraZeneca, Berlin-Chemie, Boehringer Ingelheim, Chiesi, GSK, Novartis, Orion, TEVA, and Takeda. GT and $\mathrm{AH}$ are employees of Chiesi Hungary Ltd. VM reports personal fees from GSK, AstraZeneca, Berlin Chemie, Chiesi, Boehringer Ingelheim, Novartis, Orion, and TEVA, including non-financial support from Takeda, outside the submitted work. The authors report no other conflicts of interest in this work.

\section{References}

1. World Health Organisation. Global surveillance, prevention and control of chronic respiratory diseases: a comprehensive approach; 2007. Available from: http://www.who.int/respiratory/publications/global surveillance/en/. Accessed October 16, 2018.
2. Soriano JB, Abajobir AA, Abate $\mathrm{KH}$, et al. Global, regional, and national deaths, prevalence, disability-adjusted life years, and years lived with disability for chronic obstructive pulmonary disease and asthma, 1990-2015: a systematic analysis for the Global Burden of Disease Study 2015. Lancet Respir Med. 2017;5(9):691-706. doi:10.1016/S2213-2600(17)30234-5

3. To T, Stanojevic S, Moores G, et al. Global asthma prevalence in adults: findings from the cross-sectional world health survey. $B M C$ Public Health. 2012;12:204. doi:10.1186/1471-2458-12-204

4. Global Initiative for Asthma. Global strategy for asthma management and prevention; 2018. Available from:https://ginasthma.org/2018gina-report-global-strategy-for-asthma-management-and-prevention. Accessed 16 October 2018.

5. Beasly R, Semprini A, Mitchell EA. Risk factors for asthma: is prevention possible? Lancet. 2015;386(9998):1075-1085. doi:10.10 16/S0140-6736(15)00156-7

6. Bosnic-Anticevich S, Kritikos V, Carter V, et al. Lack of asthma and rhinitis control in general practitioner-managed patients prescribed fixed-dose combination therapy in Australia. Journal of Asthma. 2018;55(6):684-694. doi:10.1080/02770903.2017.1353611

7. Price D, Fletcher M, van der Molen T. Asthma control and management in 8,000 European patients: the REcognise Asthma and LInk to Symptoms and Experience (REALISE) survey. NPJ Prim Care Respir Med. 2014;24:14009. doi:10.1038/npjpcrm.2014.9

8. van den Berge M, Ten Hacken NHT, Kerstjens HAM, Postma DS. Management of asthma with ICS and LABAs: different treatment strategies. Clin Med Ther. 2009;1:77-93.

9. Schatz M, Zeiger RS, Yang SJ, et al. The relationship of asthma impairment determined by psychometric tools to future asthma exacerbations. Chest. 2012;141(1):66-72. doi:10.1378/chest.11-0574

10. Adachi M, Hozawa S, Nishikawa M, Yoshida A, Jinnai T, Tamura G. Asthma control and quality of life in a real-life setting: a crosssectional study of adult asthma patients in Japan (ACQUIRE-2). Journal of Asthma. 2018;1-10. doi:10.1080/02770903.2018.1514628

11. Gemicioglu B, Bayram H, Cimrin A, et al. Asthma control and adherence in newly diagnosed young and elderly adult patients with asthma in Turkey. Journal of Asthma. 2019;56(5):553-561. doi:10.1080/02770903.2018.1471707

12. Muñoz X, Barreiro E, Bustamante V, Lopez-Campos JL, GonzálezBarcala FJ, Cruz MJ. Diesel exhausts particles: their role in increasing the incidence of asthma. Reviewing the evidence of a causal link. Sci Total Environ. 2019;652:1129-1138. ISSN 0048-9697. doi:10.1016/j.scitotenv.2018.10.188

13. Miller MK, Lee JH, Miller DP, Wenzel SE; TENOR Study Group. Recent asthma exacerbations: a key predictor of future exacerbations. Respir Med. 2007;101(3):481-489. doi:10.1016/j.rmed.2006.07.005

14. Melani AS, Bonavia M, Cilenti V, et al. Inhaler mishandling remains common in real life and is associated with reduced disease control. Respir Med. 2011;150(6):930-938. doi:10.1016/j. rmed.2011.01.005

15. González-Barcala F-J, García-Couceiro N, Facal D. Educación en asma. Arch Bronconeumol. 2016;52:543-544. doi:10.1016/j. arbres.2016.02.011

16. Gelzer AD, Gao W, Keleti D, et al. Multifaceted interventions improve medication adherence and reduce acute hospitalization rates in medicaid patients prescribed asthma controllers. Journal of Asthma. 2019;56(2):190-199. doi:10.1080/02770903.2018.1439954

17. Osborne ML, Pedula KL, O'Hollaren M, et al. Assessing future need for acute care in adult asthmatics: the Profile of Asthma Risk Study: a prospective health maintenance organization-based study. Chest. 2007;132(4):1151-1161. doi:10.1378/chest.05-3084

18. Barcala FJG, de la Fuente-Cid R, Álvarez-Gil R, Tafalla M, Nuevo J, Caamaño-Isorna F. Factors associated with asthma control in primary care patients: the CHAS Study. Arch Bronconeumol. 2010:46(7):358-363. ISSN 0300-2896. doi:10.1016/j.arbres.2010.01.007. 
19. Ulrik CS, Backer V, Søes-Petersen U, Lange P, Harving H, Plaschke PP. The patient's perspective: adherence or non-adherence to asthma controller therapy? J Asthma. 2006;43:701-704. doi:10.1080/ 02770900600925569

20. Bender BG, Rand C. Medication non-adherence and asthma treatment cost. Curr Opin Allergy Clin Immunol. 2004;4:191-195. doi:10.1097/00130832-200406000-00009

21. Papi A, Ryan D, Soriano JB, et al. Relationship of inhaled corticosteroid adherence to asthma exacerbations in patients with moderateto-severe asthma. J Allergy Clin Immunol Pract. 2018. doi:10.1016/j. jaip.2018.03.008

22. Chen Y, Dales R, Krewski D, Breithaupt K. Increased effects of smoking and obesity on asthma among female Canadians: the National Population Health Survey, 1994-1995. Am J Epidemiol. 1999;150(3):255-262. doi:10.1093/oxfordjournals.aje. a009996

23. Huovinen E, Kaprio J, Koskenvuo M. Factors associated to lifestyle and risk of adult onset asthma. Respir Med. 2003;97(3):273-280. doi:10.1053/rmed.2003.1419

24. Luder E, Ehrlich RI, Lou WY, Melnik TA, Kattan M. Body mass index and the risk of asthma in adults. Respir Med. 2004;98(1):2937.

25. Nystad W, Meyer HE, Nafstad P, Tverdal A, Engeland A. Body mass index in relation to adult asthma among 135,000 Norwegian men and women. Am J Epidemiol. 2004;160(10):969-976. doi:10.1093/aje/ kwh212
26. Shaheen SO, Sterne JA, Montgomery SM, Azima H. Birth weight, body mass index and asthma in young adults. Thorax. 1999;54 (5):396-402. doi:10.1136/thx.54.5.439

27. Stanley AH, Demissie K, Rhoads GG. Asthma development with obesity exposure: observations from the cohort of the National Health and Nutrition Evaluation Survey Epidemiologic Follow-up Study (NHEFS). J Asthma. 2005;42(2):97-99. doi:10.1081/JAS-51338

28. Young SY, Gunzenhauser JD, Malone KE, McTiernan A. Body mass index and asthma in the military population of the northwestern United States. Arch Intern Med. 2001;161(13):1605-1611. doi:10.1001/archinte.161.13.1605

29. Neffen $H$, Chahuàn M, Hernández DD, et al. Key factors associated with uncontrolled asthma - the Asthma Control in Latin America Study. Journal of Asthma. 2019:1-10. doi:10.1080/02770903.2018.1553050.

30. Akerman MJ, Calacanis CM, Madsen MK. Relationship between asthma severity and obesity. J Asthma. 2004;41(5):521-526.

31. Taylor B, Mannino D, Brown C, Crocker D, Twum-Baah N, Holguin F. Body mass index and asthma severity in the National Asthma Survey. Thorax. 2008;63(1):14-20. doi:10.1136/thx.2007.082784

32. Padilla-Galo A, Olveira C, Fernández de Rota-Garcia L, et al. Factors associated with bronchiectasis in patients with uncontrolled asthma; the NOPES score: a study in 398 patients. Respir Res. 2018;19:43. doi:10.1186/s12931-018-0746-7

33. Papi A, Canonica GW, Maestrelli P, et al. Rescue use of beclomethasone and albuterol in a single inhaler for mild asthma. $N$ Engl J Med. 2007;356(20):2040-2052. doi:10.1056/NEJMc063190 


\section{Supplementary materials}

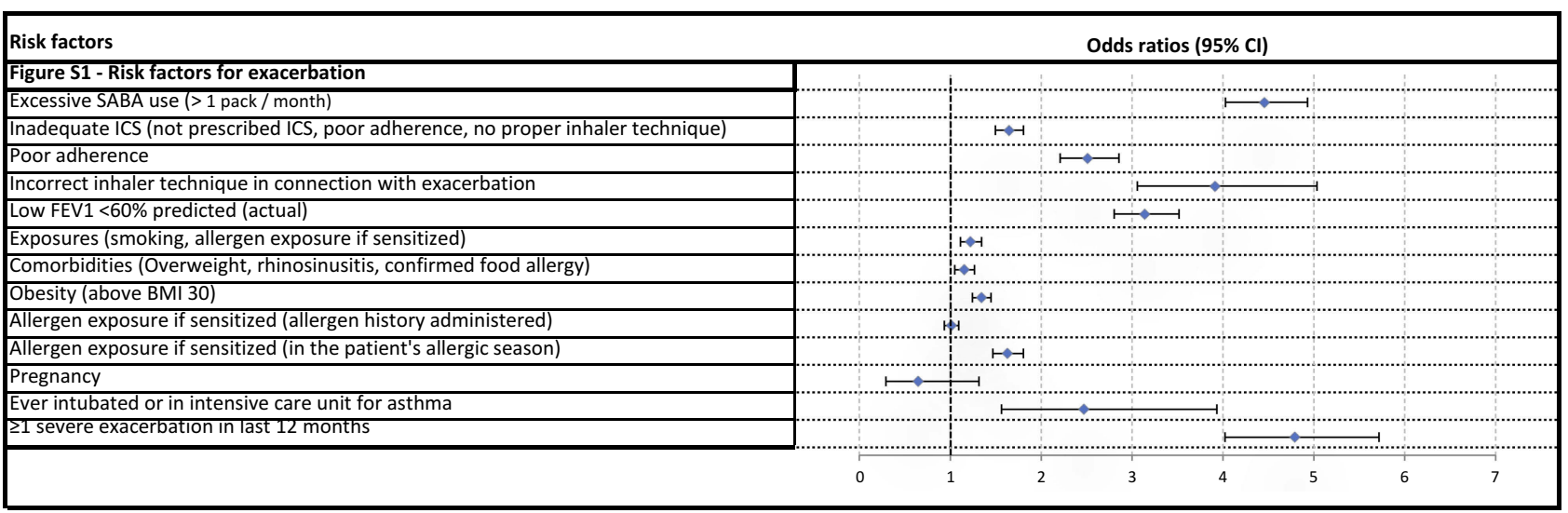

Figure SI Risk factors for exacerbation.

\begin{tabular}{|l|l|l|}
\hline Figure S2 - Risk factors for developing fixed airflow limitation \\
\hline Lack of ICS treatment & Exposures (Tobacco smoke, noxious chemicals, occupational exposures) \\
\hline Tobacco smoke (history of active smoking) & \\
\hline Smoking (currently active smokers) & \\
\hline Lowious chemicals or occupational exposures & & \\
\hline
\end{tabular}

Figure S2 Risk factors for developing fixed airflow limitation.

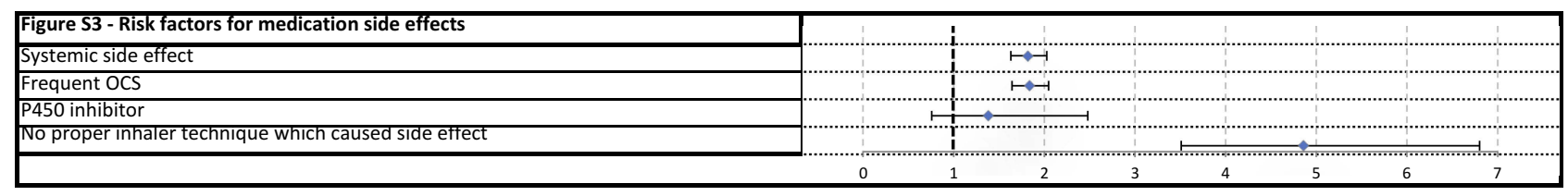

Figure S3 Risk factors for medication side effects.

Journal of Asthma and Allergy

Dovepress

\section{Publish your work in this journal}

The Journal of Asthma and Allergy is an international, peer-reviewed open-access journal publishing original research, reports, editorials and commentaries on the following topics: Asthma; Pulmonary physiology; Asthma related clinical health; Clinical immunology and the immunological basis of disease; Pharmacological interventions and

new therapies. The manuscript management system is completely online and includes a very quick and fair peer-review system, which is all easy to use. Visit http://www.dovepress.com/testimonials.php to read real quotes from published authors. 